\title{
Socioeconomic status and mortality after acute myocardial infarction: a study from Iran
}

\author{
Tahereh Donyavi ${ }^{1}$, Kourosh Holakouie Naieni', Saharnaz Nedjat ${ }^{1}$, Mariam Vahdaninia ${ }^{2}$, Mahdi Najafi ${ }^{3}$, \\ Ali Montazeri ${ }^{4^{*}}$
}

\begin{abstract}
Background: Studies have shown an inverse relationship between socioeconomic status (SES) and mortality due to coronary heart disease (CHD). Little is known about this association in Iran. This study aimed to investigate whether mortality after myocardial infarction (MI) varies by SES.

Methods: In a retrospective study, 1283 Ml patients who hospitalized in Tehran Heart Center from March 2005 to March 2006 were followed up in March 2008. Demographic, clinical and SES data were collected from case records and by telephone interviews. Multiple logistic regression analysis was performed to estimate the predictive effect of socioeconomic factors on outcome.

Results: In all 664 patients were studied. Of these, 500 patients were alive and 164 were dead due to Ml (64 died at hospital and 100 died at home). The results of regression analysis showed that in addition to treatment $(\mathrm{OR}=$ 9.52, $95 \% \mathrm{Cl} 4.84-18.7)$, having diabetes $(\mathrm{OR}=1.78,95 \% \mathrm{Cl} 1.12-2.81)$ or hyperlipidemia $(\mathrm{OR}=1.82,95 \% \mathrm{Cl} 1.14-$ 2.90), socioeconomic variables including living area in square per person (lowest level vs. upper level $O R=4.92$, $95 \% \mathrm{Cl} 2.11$-11.4), unemployment $(\mathrm{OR}=3.50,95 \% \mathrm{Cl} 1.50-8.13$ ) and education (OR for illiterate patients $=2.51,95 \%$ $\mathrm{Cl}$ 1.00-6.31) were the most significant contributing factors to increased mortality after Ml.

Conclusion: Although the findings should be interpreted with caution, the study results indicated that socioeconomic variables were significant contributing factors to increased mortality after myocardial infarction. The underlying role of socioeconomic status on increased mortality after Ml deserves further investigation.
\end{abstract}

\section{Background}

Coronary heart disease (CHD) is the first killer of Iranian population. Annually there are about 138,000 deaths due to CHD (about $40 \%$ of total deaths). A bout $50 \%$ of deaths occur due to myocardial infarction [1]. It is a leading cause of morbidity and disability in Iranian population [2]. Since no efficient referral system exists in Iran, people with heart diseases directly attend to private sector, clinics or state hospitals and seen by internal medicine specialist or cardiologist. Patients with myocardial infarction (MI) usually attend to private, state or teaching hospitals as emergency admissions. According to patients' medical coverage they should pay for their care. There is evidence that the number of patients with MI are increasing and during a five-year period for

\footnotetext{
* Correspondence: montazeri@acecr.ac.ir

${ }^{4}$ Department of Mental Health, Iranian Institute for Health Sciences Research, ACECR, Tehran, Iran

Full list of author information is available at the end of the article
}

instance cardiac surgery increased by $80 \%$ in a teaching hospital [3]. Recently, Iranian ministry of health implemented different preventive measures including creating different centers for cardiovascular diseases control.

In addition to known risk factors for CHD [4] it appears that people's socioeconomic status also contributes to the outcome. The association between socioeconomic position and outcome of myocardial infarction (MI) is generally well documented in western countries indicating that those with lower socioeconomic status experience the most burden of the condition [5-10]. A historical study among British civil servants in 1981 found that social class (as measured by occupation) was a significant contributing factor to increased risk of CHD while age, smoking, height, body mass index, systolic blood pressure, cholesterol and blood glucose showed only a moderate impact [11]. Similarly a study from the USA found that disadvantaged acute MI 
patients receive fewer specialized procedures and therefore show higher mortality due to CHD [12].

Much attention has been paid to how socioeconomic status (SES) might play a role on the outcome of CHD. There has been a debate if geographical service patterns and accessibility to medical care are responsible for such an association. For instance a study from Canada found that geography and service supply do not explain socioeconomic gradients in angiography use after acute myocardial infarction [13]. Further analysis of the same study indicated that upper middle-class Canadians gain preferential access to services within the publicly funded health care system as compared to those with lower incomes or less educated individuals [14]. However, consequent studies from the same country showed that there were geographical barriers to cardiac catheterisation and MI patients who live outside of metropolitan area and they had lower rates of cardiac catheterisation, longer waiting times and increased rate of readmission, and thus poorer outcomes [15].

Little is known about the association of SES and outcome of CHD in developing countries such as Iran. However recently the Isfahan Cardiovascular Research Centre (a WHO collaborating center for research and training in cardiovascular disease control in central Iran) carried out an analysis of available data of 12514 individuals and found that socioeconomic factors as measured by education, occupation and income were associated with cardiovascular risk factors [16]. The study reported mixed results and did not indicate the association between the adverse outcome of the disease and socioeconomic variables.

The main objective of this study was to investigate whether socioeconomic variables independently contribute to excess mortality after myocardial infarction in Iran. We thought the findings from this first study could contribute to existing literature on the topic and also could provide evidence for better understanding of social determinants of health in general and the issue of health equity in particular in Iran and perhaps in other developing countries of similar conditions.

\section{Methods}

\section{Design}

This was a retrospective study of a cohort of $1283 \mathrm{MI}$ patients who admitted to Tehran Heart Center, a large teaching and referral hospital affiliated to Tehran University of Medical Sciences between March 2005 and March 2006 (one complete Iranian calendar year). All case records were reviewed and patients' clinical records were extracted. Patients were followed-up in March 2008 in order to find out whether they were still alive. One of us contacted all patients' by telephone. In each successful contact either patient or a close relative (wife, husband, son or daughter, parents and sister or brother) were interviewed. For each unsuccessful contact two extra attempts were made and if still could not find the patient, it was regarded as missing.

\section{Demographic information}

Demographic data included recording of age, gender, marital status, and employment.

\section{Clinical information}

This included information on body mass index (BMI), and known risk factors for myocardial infarction. The risk factors were: history of high blood pressure (blood pressure equal of greater than $130 / 85 \mathrm{mmGH}$ ), diabetes (fasting blood glucose equal or greater than $126 \mathrm{mg} / \mathrm{dl}$ ), hyperlipidemia (cholesterol equal or greater than 200 $\mathrm{mg} / \mathrm{dl}$ and triglyceride equal or grater than $150 \mathrm{mg} / \mathrm{dl}$ ), and smoking. BMI was categorized as recommended by the WHO: normal range $\left(\mathrm{BMI}=18.5-24.9 \mathrm{~kg} / \mathrm{m}^{2}\right)$, overweight $\left(\mathrm{BMI}=25-29.9 \mathrm{~kg} / \mathrm{m}^{2}\right)$, and obese $(\mathrm{BMI} \geq 30$ $\mathrm{kg} / \mathrm{m}^{2}$ ) [17]. Information regarding treatment also was collected. Patients received either invasive (coronary artery by pass graft) or non-invasive (pharmacologic) treatments. Non-surgical treatment included prescriptions of aspirin, beta-adrenergic blocking agents $(\beta$ blockers) and angiotensin-converting enzyme (ACE) inhibitors. The decision regarding mode of therapy depended upon the individual patient's prognosis as determined by both cardiac and non-cardiac conditions. In general patients who were at higher risk as defined by the severity of angina and/or ischemia, the number of diseased vessels, and the presence of left ventricular dysfunction received surgical treatment. Data were extracted from case records.

\section{Socioeconomic measures}

We used years of formal education as a measure for social position. There is evidence that it is a valid and reliable indicator for studies of association between health and social status in Iran [18]. Education was categorized into five levels: no education, first level (1 to 5 years), second level (6-9 years), third level (10-12 years) and fourth level (more than 12 years). Economic status was assessed by average living area in square per person $\left(\mathrm{m}^{2} / \mathrm{p}\right)$. This proxy measure was categorized into four levels: less than 10,10-19, 20-39, and equal or more than 40 square per person living area. Since income information in Iran is not reliable and people usually have more than one job at the same time, we did not collect or use data on income as a measure of socioeconomic position. Years of education were extracted from case records but average living area per person was calculated based on information collected during interviews. 
Table 1 Demographic and clinical characteristics of the study population

\begin{tabular}{|c|c|c|c|c|}
\hline & Study population $(n=1283)$ & Study sample $(n=664)$ & Drop-out sample $(n=619)$ & \\
\hline & No. (\%) & No. (\%) & No. (\%) & $\mathbf{P}$ \\
\hline Age (years) & & & & 0.15 \\
\hline$\leq 49$ & $214(16.7)$ & $105(15.8)$ & 109 (17.6) & \\
\hline 50-59 & $304(23.7)$ & $144(21.7)$ & $160(25.8)$ & \\
\hline 60-69 & $363(28.3)$ & $193(29.1)$ & $170(27.5)$ & \\
\hline$\geq 70$ & $402(31.3)$ & $222(33.4)$ & $180(29.1)$ & \\
\hline Mean (SD) & $62.4(12.3)$ & $63.0(12.0)$ & $61.7(12.7)$ & $0.05^{*}$ \\
\hline Range & $21-103$ & $21-91$ & $26-103$ & \\
\hline Gender & & & & 0.003 \\
\hline Male & $950(74.0)$ & $468(70.5)$ & $482(77.9)$ & \\
\hline Female & $333(26.0)$ & $196(29.5)$ & $137(22.1)$ & \\
\hline Marital status & & & & 0.11 \\
\hline Single & $42(3.3)$ & $24(3.6)$ & $18(2.9)$ & \\
\hline Married & $1024(79.8)$ & $515(77.6)$ & $509(82.2)$ & \\
\hline Widowed/divorced & $217(16.9)$ & $125(18.8)$ & $92(14.9)$ & \\
\hline Education (years) & & & & 0.95 \\
\hline 0 & $337(26.3)$ & $177(26.7)$ & $160(25.8)$ & \\
\hline $1-5$ & $285(22.3)$ & $145(21.8)$ & $140(22.6)$ & \\
\hline $6-9$ & $313(24.4)$ & $160(24.1)$ & $153(24.7)$ & \\
\hline $10-12$ & $218(16.9)$ & $111(16.7)$ & $107(17.2)$ & \\
\hline$>12$ & $130(10.1)$ & $71(10.7)$ & $59(9.5)$ & \\
\hline Employment & & & & 0.06 \\
\hline Housewife & $282(22.0)$ & 157 (23.6) & $125(20.2)$ & \\
\hline Employed & $615(47.9)$ & $297(44.7)$ & $318(51.4)$ & \\
\hline Unemployed & $115(9.0)$ & $68(10.2)$ & $47(7.6)$ & \\
\hline Retired & $271(21.1)$ & $142(21.4)$ & $129(20.8)$ & \\
\hline BMI $\left(\mathrm{kg} / \mathrm{m}^{2}\right)^{*}$ & & & & 0.25 \\
\hline$\leq 24.9$ & $362(28.3)$ & $180(27.1)$ & $182(29.4)$ & \\
\hline $25-29.9$ & $728(56.7)$ & $374(56.3)$ & $354(57.2)$ & \\
\hline$\geq 30$ & $193(15.0)$ & $110(16.6)$ & $83(13.4)$ & \\
\hline Hypertension & & & & 0.44 \\
\hline No & $703(54.8)$ & $357(53.8)$ & $346(55.9)$ & \\
\hline Yes & $580(45.2)$ & $307(46.2)$ & $273(44.1)$ & \\
\hline Diabetes & & & & 0.99 \\
\hline No & $833(64.9)$ & $431(64.9)$ & $402(64.9)$ & \\
\hline Yes & $450(35.1)$ & $233(35.1)$ & $217(35.1)$ & \\
\hline Hyperlipidemia & & & & 0.43 \\
\hline No & $601(46.8)$ & $304(45.8)$ & $297(48.0)$ & \\
\hline Yes & $682(53.2)$ & $360(54.2)$ & $322(52.0)$ & \\
\hline History of smoking & & & & 0.03 \\
\hline No & $416(32.4)$ & $198(29.8)$ & $218(35.2)$ & \\
\hline Yes & 867 (67.6) & $466(70.2)$ & $4.01(64.8)$ & \\
\hline Treatment & & & & $<0.0001^{* *}$ \\
\hline Coronary artery bypass graft & $333(26.0)$ & $232(34.9)$ & $101(16.3)$ & \\
\hline Non-surgical & $950(74.0)$ & $432(65.1)$ & $518(83.7)$ & \\
\hline
\end{tabular}

* t-test.

** Fisher's exact test. 
Table 2 Demographic and clinical characteristics of the study sample $(n=664)$

\begin{tabular}{|c|c|c|c|}
\hline & Discharged $(n=500)$ & Dead $(n=164)$ & \\
\hline & No. (\%) & No. (\%) & $P$ \\
\hline Age (years) & & & $<0.0001$ \\
\hline$\leq 49$ & $90(18.0)$ & $15(9.1)$ & \\
\hline $50-59$ & $121(24.2)$ & $23(14.0)$ & \\
\hline $60-69$ & $152(30.4)$ & $41(25.0)$ & \\
\hline$\geq 70$ & $137(27.4)$ & $85(51.8)$ & \\
\hline Mean (SD) & $61.5(11.6)$ & $67.6(12.1)$ & $<0.0001^{*}$ \\
\hline Range & $21-88$ & 29-91 & \\
\hline Gender & & & $<0.0001$ \\
\hline Male & $374(74.8)$ & $94(57.3)$ & \\
\hline Female & $126(25.2)$ & $70(42.7)$ & \\
\hline Marital status & & & $<0.0001$ \\
\hline Single & $21(4.2)$ & $3(1.8)$ & \\
\hline Married & $406(81.2)$ & $109(66.5)$ & \\
\hline Widowed/divorced & $73(14.6)$ & $52(31.7)$ & \\
\hline Education (years) & & & $<0.0001$ \\
\hline 0 & $104(20.8)$ & $73(44.5)$ & \\
\hline $1-5$ & $107(21.4)$ & $38(23.2)$ & \\
\hline $6-9$ & $132(26.4)$ & $28(17.1)$ & \\
\hline$\overline{10-12}$ & $94(18.8)$ & $17(10.4)$ & \\
\hline$>12$ & $63(12.6)$ & $8(4.9)$ & \\
\hline Employment & & & $<0.0001$ \\
\hline Housewife & $108(21.6)$ & 49 (29.9) & \\
\hline Employed & $249(49.8)$ & $48(29.3)$ & \\
\hline Unemployed & $30(6.0)$ & $38(23.2)$ & \\
\hline Retired & $113(22.6)$ & $29(17.7)$ & \\
\hline Living area in square per person $\left(\mathrm{m}^{2} / \mathrm{p}\right)$ & & & 0.001 \\
\hline$<10$ & $52(10.4)$ & $29(17.7)$ & \\
\hline $10-19$ & $186(37.2)$ & $78(47.6)$ & \\
\hline $20-39$ & $171(34.2)$ & $41(25.0)$ & \\
\hline$\geq 40$ & $91(18.2)$ & $16(9.8)$ & \\
\hline BMI $\left(\mathrm{kg} / \mathrm{m}^{2}\right)^{*}$ & & & 0.06 \\
\hline$\leq 24.9$ & $145(29.0)$ & $35(21.4)$ & \\
\hline $25-29.9$ & $269(53.8)$ & $105(64.0)$ & \\
\hline$\geq 30$ & $86(17.2)$ & $24(14.6)$ & \\
\hline Hypertension & & & 0.04 \\
\hline No & $280(56.0)$ & $77(47.0)$ & \\
\hline Yes & $220(44.0)$ & $87(53.0)$ & \\
\hline Diabetes & & & 0.001 \\
\hline No & $343(68.6)$ & $88(53.7)$ & \\
\hline Yes & $157(31.4)$ & $76(46.3)$ & \\
\hline Hyperlipidemia & & & 0.10 \\
\hline$\overline{\text { No }}$ & $238(47.6)$ & $66(40.2)$ & \\
\hline$\overline{\text { Yes }}$ & $262(52.4)$ & $98(59.8)$ & \\
\hline
\end{tabular}


Table 2 Demographic and clinical characteristics of the study sample $(n=664)$ (Continued)

\begin{tabular}{|c|c|c|c|}
\hline History of smoking & & & 0.01 \\
\hline No & $162(32.4)$ & $36(22.0)$ & \\
\hline$\overline{Y e s}$ & $338(67.6)$ & $128(78.0)$ & \\
\hline Treatment & & & $<0.0001$ \\
\hline Coronary artery bypass graft & $221(44.2)$ & $11(6.7)$ & \\
\hline Non-surgical & $279(55.8)$ & $153(93.3)$ & \\
\hline
\end{tabular}

\section{Statistical analysis}

In addition to descriptive statistics, multiple logistic regression analysis was performed to calculate odds ratios (ORs) and to examine the predictive effect of socioeconomic and clinical variables on risk for mortality after myocardial infarction. For the analyses patients' status (alive vs. dead) was considered as independent variable. Socio-demographic and clinical information were regarded as dependent factors and all were entered into the model. We carried out analyses for in-hospital and out-of-hospital deaths separately, in addition to presenting the combined analyses. All the deaths examined in the present study were cardiac deaths.

\section{Results}

\section{Patients' characteristics}

In all 1283 patients were admitted to the Tehran Heart Center between March 2005 and March 2006. After a two-year fallow-up only 664 patients were available for the study. Of these, 500 patients were alive and 164 were dead due to myocardial infarction (65 died at hospital and 99died at home). The socio-demographic and clinical characteristics of patients are presented in Table 1 and Table 2.

\section{Outcome analysis}

Using patients' status (alive or dead) as outcome variable, we performed multiple logistic regression analysis while entering patients' socio-demographic and clinical characteristics as independent variables in the model. The results for in- and out-of-hospital deaths are shown in Table 3 and Table 4 separately. The combined results are shown in Table 5 . The findings indicated that in addition to treatment $(\mathrm{OR}=9.52,95 \% \mathrm{CI} 4.84-18.7)$, having diabetes $(\mathrm{OR}=1.78,95 \% \mathrm{CI} 1.12-2.81)$ or hyperlipidemia $(\mathrm{OR}=1.82$, 95\% CI 1.14-2.90), socioeconomic variables including living area in square per person (lowest level vs. upper level OR $=4.92,95 \%$ CI 2.11-11.4), unemployment $(\mathrm{OR}=3.50,95 \% \mathrm{CI} 1.50-8.13)$ and education (OR for illiterate patients $=2.51,95 \%$ CI 1.00 6.31) were the most significant contributing factors to increased mortality after myocardial infarction.

\section{Discussion}

This study investigated whether survival after MI varied with socio-economic status and analyzed a two-years mortality rate among $664 \mathrm{MI}$ patients who hospitalized in Tehran Heart Center during a one complete calendar year. The results obtained from regression analysis adjusted for demographic, clinical and socio-economic variables showed that education was a predictor of mortality among patients with MI. The lower educational level group (illiterate and primary) showed higher mortality risk compared to the higher level group. The association between education and mortality due to MI is well documented where studies showed that patients with lower educational levels experience lower survival rates after an acute $\mathrm{MI}$ attack $[19,20]$. In addition there is evidence that years of education can strongly contribute in the distribution of several risk factors for CHD such as smoking and HBP that may well inversely have an effect on the incidence and impact of MI attack [21].

The results also indicated that unemployed and retired individuals showed a higher risk of mortality after MI (P $=0.004)$. Earlier surveys have found income as an independent factor for outcome following MI. In fact, lower income was associated with increased short and longterm mortality [22,23]. Even though a study from Canada has stated that the effect of income on mortality rate due to MI can be modified by age, past cardiovascular events and current vascular risk factors [24].

Economic status as measured by 'living area in square per person' demonstrated a strong correlation with mortality caused by MI. It was found that people who were living in larger places have experienced decreased mortality after MI. Similarly in a follow-up study in Sweden it was revealed that socioeconomic environment plays an essential role in the survival rate of patients with MI and worse long term prognosis is expected for patients from less affluent residential areas [25]. A study investigated the hypothesis that how the neighbourhood status may link to cardiovascular risk factors and excess mortality rate. This study was carried out in nine industrial towns from Czech Republic and Germany and pointed out that area level socioeconomic is associated with health related 
Table 3 The results obtained from multiple logistic regression analysis indicating risk factors for mortality after myocardial infarction for in-hospital deaths ( $n=500$ alive vs. 65 in-hospital deaths)

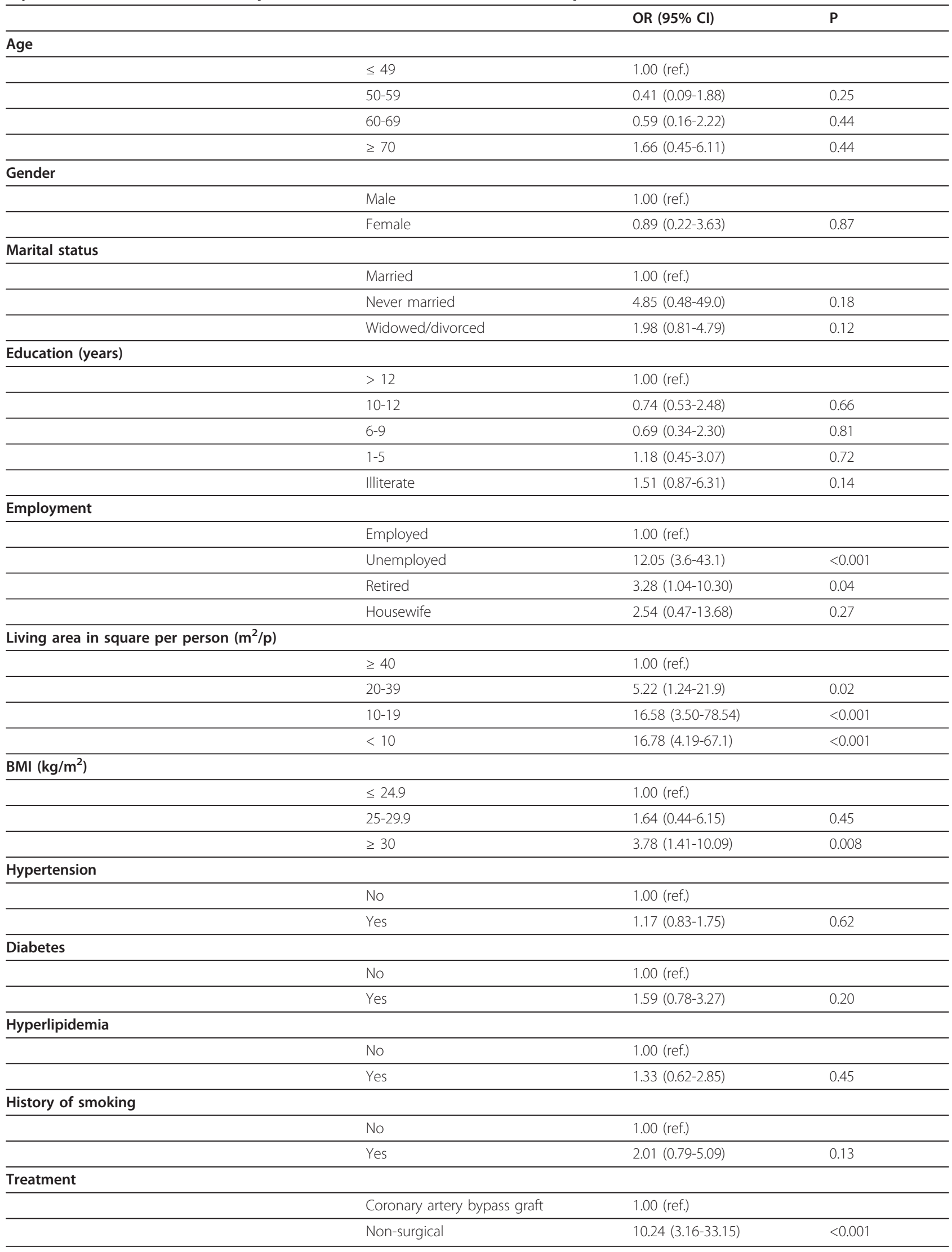


Table 4 The results obtained from multiple logistic regression analysis indicating risk factors for mortality after myocardial infarction for out-of-hospital deaths ( $n=500$ alive vs. 99 out-of-hospital deaths)

\begin{tabular}{|c|c|c|c|}
\hline & & OR $(95 \% \mathrm{Cl})$ & $P$ \\
\hline \multicolumn{4}{|c|}{ Age } \\
\hline & $\leq 49$ & 1.00 (ref.) & \\
\hline & $50-59$ & $1.47(0.58-3.73)$ & 0.41 \\
\hline & $60-69$ & $1.36(0.53-3.45)$ & 0.51 \\
\hline & $\geq 70$ & $1.86(0.72-4.77)$ & 0.19 \\
\hline \multicolumn{4}{|c|}{ Gender } \\
\hline & Male & 1.00 (ref.) & \\
\hline & Female & $3.83(1.26-11.59)$ & 0.01 \\
\hline \multicolumn{4}{|c|}{ Marital status } \\
\hline & Married & 1.00 (ref.) & \\
\hline & Never married & $0.99(0.19-5.08)$ & 0.99 \\
\hline & Widowed/divorced & $0.60(0.27-1.31)$ & 0.20 \\
\hline \multicolumn{4}{|c|}{ Education (years) } \\
\hline & $>12$ & 1.00 (ref.) & \\
\hline & $10-12$ & $0.60(0.20-1.83)$ & 0.37 \\
\hline & $6-9$ & $0.61(0.22-1.72)$ & 0.35 \\
\hline & $1-5$ & $1.01(0.37-2.76)$ & 0.98 \\
\hline & Illiterate & $1.82(0.69-4.78)$ & 0.22 \\
\hline \multicolumn{4}{|c|}{ Employment } \\
\hline & Employed & 1.00 (ref.) & \\
\hline & Unemployed & $1.27(0.62-2.57)$ & 0.50 \\
\hline & Retired & $0.95(0.28-3.20)$ & 0.93 \\
\hline & Housewife & $0.41(0.12-1.35)$ & 0.14 \\
\hline \multicolumn{4}{|c|}{ Living area in square per person $\left(\mathrm{m}^{2} / \mathrm{p}\right)$} \\
\hline & $\geq 40$ & 1.00 (ref.) & \\
\hline & $20-39$ & $1.78(0.81-3.92)$ & 0.15 \\
\hline & $10-19$ & $2.56(1.18-5.52)$ & 0.01 \\
\hline & $<10$ & $3.25(1.27-8.29)$ & 0.01 \\
\hline \multicolumn{4}{|c|}{ BMI $\left(\mathrm{kg} / \mathrm{m}^{2}\right)$} \\
\hline & $\leq 24.9$ & 1.00 (ref.) & \\
\hline & $25-29.9$ & $1.05(0.56-1.78)$ & 0.98 \\
\hline & $\geq 30$ & $1.06(0.47-2.11)$ & 0.99 \\
\hline \multicolumn{4}{|c|}{ Hypertension } \\
\hline & No & 1.00 (ref.) & \\
\hline & Yes & $1.16(0.68-1.98)$ & 0.57 \\
\hline \multicolumn{4}{|c|}{ Diabetes } \\
\hline & No & 1.00 (ref.) & \\
\hline & Yes & $1.92(1.13-3.27)$ & 0.01 \\
\hline \multicolumn{4}{|c|}{ Hyperlipidemia } \\
\hline & No & 1.00 (ref.) & \\
\hline & Yes & $2.16(1.24-3.74)$ & 0.006 \\
\hline \multicolumn{4}{|c|}{ History of smoking } \\
\hline & No & 1.00 (ref.) & \\
\hline & Yes & $1.10(0.58-2.10)$ & 0.75 \\
\hline \multicolumn{4}{|c|}{ Treatment } \\
\hline & Coronary artery bypass graft & 1.00 (ref.) & \\
\hline & Non-surgical & $9.64(4.26-21.83)$ & $<0.001$ \\
\hline
\end{tabular}


Table 5 The results obtained from multiple logistic regression analysis indicating risk factors for mortality after myocardial infarction for all deaths ( $n=500$ alive vs. 164 in- and out-of-hospital deaths combined)

\begin{tabular}{|c|c|c|c|}
\hline & & OR $(95 \% \mathrm{Cl})$ & $\mathbf{P}$ \\
\hline \multicolumn{4}{|l|}{ Age } \\
\hline & $\leq 49$ & 1.00 (ref.) & \\
\hline & $50-59$ & $1.12(0.49-2.52)$ & 0.78 \\
\hline & $60-69$ & $1.18(0.53-2.59)$ & 0.68 \\
\hline & $\geq 70$ & $1.97(0.89-4.36)$ & 0.09 \\
\hline \multicolumn{4}{|c|}{ Gender } \\
\hline & Male & 1.00 (ref.) & \\
\hline & Female & $2.22(0.86-5.69)$ & 0.09 \\
\hline \multicolumn{4}{|c|}{ Marital status } \\
\hline & Married & 1.00 (ref.) & \\
\hline & Never married & $1.47(0.36-5.95)$ & 0.58 \\
\hline & Widowed/divorced & $0.92(0.50-1.72)$ & 0.06 \\
\hline \multicolumn{4}{|c|}{ Education (years) } \\
\hline & $>12$ & 1.00 (ref.) & \\
\hline & $10-12$ & $0.91(0.33-2.48)$ & 0.86 \\
\hline & $6-9$ & $0.89(0.34-2.30)$ & 0.81 \\
\hline & $1-5$ & $1.18(0.45-3.07)$ & 0.72 \\
\hline & Illiterate & $2.51(1.00-6.31)$ & 0.04 \\
\hline \multicolumn{4}{|c|}{ Employment } \\
\hline & Employed & 1.00 (ref.) & \\
\hline & Unemployed & $3.50(1.50-8.13)$ & 0.004 \\
\hline & Retired & $1.18(0.79-2.77)$ & 0.21 \\
\hline & Housewife & $0.67(0.23-1.94)$ & 0.46 \\
\hline \multicolumn{4}{|c|}{ Living area in square per person $\left(\mathrm{m}^{2} / \mathrm{p}\right)$} \\
\hline & $\geq 40$ & 1.00 (ref.) & \\
\hline & $20-39$ & $2.34(1.14-4.79)$ & 0.01 \\
\hline & $10-19$ & $4.38(2.19-8.75)$ & $<0.0001$ \\
\hline & $<10$ & $4.92(2.11-11.4)$ & $<0.0001$ \\
\hline \multicolumn{4}{|c|}{ BMI $\left(\mathrm{kg} / \mathrm{m}^{2}\right)$} \\
\hline & $\leq 24.9$ & 1.00 (ref.) & \\
\hline & $25-29.9$ & $1.43(0.85-2.41)$ & 0.17 \\
\hline & $\geq 30$ & $1.09(0.55-2.17)$ & 0.78 \\
\hline \multicolumn{4}{|c|}{ Hypertension } \\
\hline & No & 1.00 (ref.) & \\
\hline & Yes & $1.05(0.66-1.66)$ & 0.81 \\
\hline \multicolumn{4}{|c|}{ Diabetes } \\
\hline & No & 1.00 (ref.) & \\
\hline & Yes & $1.78(1.12-2.81)$ & 0.01 \\
\hline \multicolumn{4}{|c|}{ Hyperlipidemia } \\
\hline & No & 1.00 (ref.) & \\
\hline & Yes & $1.82(1.14-2.90)$ & 0.01 \\
\hline \multicolumn{4}{|c|}{ History of smoking } \\
\hline & No & 1.00 (ref.) & \\
\hline & Yes & $1.33(0.77-2.31)$ & 0.30 \\
\hline \multicolumn{4}{|c|}{ Treatment } \\
\hline & Coronary artery bypass graft & 1.00 (ref.) & \\
\hline & Non-surgical & $9.52(4.84-18.7)$ & $<0.0001$ \\
\hline
\end{tabular}


lifestyles which might be a possible pathway linking social status and cardiovascular diseases [26].

Receiving non-surgical treatment was a significant prognostic factor for higher mortality. We do not know the exact reasons for not receiving surgical treatment; nevertheless we do speculate that patients' economic status was one of the most possible reasons. Evidence suggests that financial difficulties among patients with MI are the main factors that can cause poorer outcome and elevated possibility of re-hospitalization [27]. A strong association was reported between early recurrent ischaemic occurrences and SE deprivation that was not accounted for by clinical presentation or treatment [28]. However, there might be two other additional explanations for such an observation: the patients did not have medical indications for surgery, and that patients themselves preferred other treatments. Future studies should clearly ask patients about this in order to indicate whether they could not afford surgery or irrespective of financial issues they received other treatments.

\section{Limitations}

This study has several limitations. The most important concern is that there was a large-drop-out. Studies have shown a higher mortality risk in non-responders to a baseline survey adjusted for different measures of patients' socio-economic status. For instance Harald et al. [29] found a 2-fold higher mortality risk in nonresponders to baseline in every socioeconomic category. Similarly Ferrie et al. [30] showed that non-responder to baseline had a mortality hazard double that for responders. Secondly, this study only included a patient population admitted to a single hospital. Earlier studies from other countries have reported rather large socioeconomic differences in mortality outside hospital (before reaching the hospital) and in the current study little can be said about them. It is recommended that the future studies should also investigate about patients who die before hospital admission. Thirdly, since the data was collected from one hospital, the results could not be generalized to the whole country. However, we believe the findings from this study are accurate since information presented here were extracted or collected with caution. In general the completeness and accuracy of case records in Iran (especially in teaching hospitals) are relatively good $[31,32]$. In addition studies have shown that information regarding demographic and socio-economic variables such as age, marital status, education or living conditions that are collected by interviews are valid $[18,33]$.

In general the findings of current survey provided obvious evidence of the converse relationship between socio-economic variables and mortality after MI in Iranian patients. Coronary heart conditions are a main cause of mortality in Iranian population and can cause major work absenteeism $[1,34]$. The burden of CHD on the Iranian oil industry in 1999 to 2000 was examined and its direct cost was estimated about 22,770 million Iranian Rials $(10,000$ Rls. $=1$ US\$) [34]. Taking into consideration the underlying factors on high fatality due to CHD in Iran might have an essential role in understanding alleviating burden of the situation. Therefore, these findings may serve as possible recommendation for Iranian health policy.

\section{Conclusion}

Although the findings should be interpreted with caution, the study results indicated that socioeconomic variables were significant contributing factors to increased mortality after myocardial infarction. The underlying role of socioeconomic status on increased mortality after MI should be further studied.

\section{Author details}

${ }^{1}$ School of Public Health, Tehran University of Medical Sciences, Tehran, Iran. ${ }^{2}$ Department of Social Medicine, Iranian Institute for Health Sciences

Research, ACECR, Tehran, Iran. ${ }^{3}$ Department of Anesthesiology, Tehran Heart Centre, Tehran University of Medical Sciences, Tehran, Iran. ${ }^{4}$ Department of Mental Health, Iranian Institute for Health Sciences Research, ACECR, Tehran, Iran.

\section{Authors' contributions}

TD was the main investigator, and collected the data. $\mathrm{KH}$ contributed to the study design and analysis. SN contributed to statistical analysis. MV contributed to writing process. MN advised on clinical aspects of the study and contributed to the discussion. AM initiated the study, analyzed the data and wrote the final draft. All authors read and approved the manuscript.

\section{Competing interests}

The authors declare that they have no competing interests.

Received: 4 May 2010 Accepted: 7 February 2011

Published: 7 February 2011

\section{References}

1. Naghavi M, Jafari N: Death Profile in Iran, 2005 Tehran: Iranian Ministry of Health; 2007.

2. Hatmi ZN, Tahvildari S, Gafarzadeh Motlag A, Sabouri Kashani A: Prevalence of coronary artery disease risk factors in Iran: s population based study. BMC Cardiovascular Disorders 2007, 7:32.

3. Karimi AA, Ahmadi H, Davoodi S, Marzban M, Abbasi K, Movahedi N, Salehi Omran A, Shirzad M, Abbasi SH, Lotfi-Tokaldany M: Tehran Heart Centre adult cardiac surgery database: a report of 5-year registry. Paper present at the 19the Scientific Session of the Saudi Heart Association. Riyadh, Saudi Arabia; 2008.

4. Yusuf S, Hawken S, Ounpuu S, Dans T, Avezum A, Lanas F, Mcqueen M, Budaj A, Pais P, Varigos J, Lisheng L: Effect of potentially modifiable risk factors associated with myocardial infarction in 52 countries (the INTER HEART study): case-control study. Lancet 2004, 364:937-952.

5. Sproston K, Primatesta P, Eds: In Health survey for England 2003, Cardiovascular disease. Volume 1. London: The Stationary Office; 2003.

6. Lawlor DA, Smith GD, Patel R, Ebrahim Sh: Life-course socioeconomic position, area deprivation and coronary heart disease: findings from the British women's heart and health study. Am J Public Health 2005, 95:91-97.

7. Kaplan GA, Keil JE: Socio-economic factors and cardiovascular disease: a review of the literature. Circulation 1993, 88:1973-1998. 
8. Kolegard Stjarne M, Diderichsen F, Reuterwall C, Hallqvist J: Socioeconomic context in areas of living and risk of myocardial infarction: results from Stockholm Heart Epidemiology Progaram (SHEEP). J Epidemiol Community Health 2002, 56:29-35.

9. Alboni P, Amadei A, Scarfo S, Bettiol K, Ippolito F, Baggioni G: In industrialised nations, a low socioeconomic status represents an independent predictor of mortality in patients with acute myocardial infarction. Ital Heart J 2003, 4:551-558.

10. Gerward S, Tyden P, Hansen O, Engstrom G, Janzon L, Hedblad B: Survival rate 28 days after hospital admission with first myocardial infarction. Inverse relationship with socio-economic circumstances. J Intern Med 2006, 256:164-172

11. Rose G, Marmot MG: Social class and coronary heart disease. Br Heart J 1981, 45:13-19.

12. Shen JJ, Wan TT, Perlin JB: An exploration of the complex relationship of socioecologic factors in the treatment and outcomes of acute myocardial infarction in disadvantaged populations. Health Serv Res 2001, 36:711-732.

13. Alter DA, Naylor CD, Austin PC, Chan BT, Tu JV: Geography and service supply do not explain socioeconomic gradients in angiography use after acute myocardial infarction. CMAJ 2003, 4:261-264.

14. Alter DA, Iron K, Austin PC, Naylor CD, SESAMI Study Group: Socioeconomic status, service patterns, and perceptions of care among survivors of acute myocardial infarction in Canada. JAMA 2004, 291:1100-1107.

15. Hassan A, Pearce NJ, Mathers J, Veugelers PJ, Hirsch GM, Cox JL, Improving Cardiovascular Outcomes in Nova Scotia Investigators: The effect of place of residence on access to invasive cardiac services following acute myocardial infarction. Can J Cardiol 2009, 25:207-212.

16. Bahonar A, Sarrafzadegan N, Kelishadi R, Shirani S, Ramezani MA, Taghdisi MH, Gharipour M: Association of socioeconomic profiles with cardiovascular risk factors in Iran: the Isfahan Healthy Heart Program. Int J Public Health 2011, 56:37-44.

17. World Health Organization (WHO), Obesity and overweight (Fact sheet No. 311). [http://www.who.int/mediacentre/factsheets/fs311/en/index.html].

18. Montazeri A, Goshtasebi A, Vahdaninia M: Educational inequalities in selfreported health in a general Iranian population. BMC Research Notes 2008, 1:50.

19. Salomaa $V$, Niemela M, Miettinen $H$, Ketonen M, Immonen-Raiha $P$, Koshinen S, Mahonen M, Letho S, Vourenma T, Palomaki P, Mustaniemi H, Kaarsalo E, Arstilla M, Torppa J, Kuulasmaa K, Puska P, Pyorala K, Toumilehto J: Relationship of socioeconomic status to the incidence and prehospital, 28-day, and 1-year mortality rates of acute coronary events in the FINMONICA myocardial infarction register study. Circulation 2000, 101:1913-1918.

20. Alter DA, Iron K, Naylor CD, SESAMI Study Group: Influence of education and income on atherogenic risk factor profiles among patients hospitalised with acute myocardial infarction. Can J Cardiol 2004, 20:1219-1228.

21. Yarnell J, Yu S, McCrum E, Arveiler D, Hass B, Dallongeville J, Montaye M, Amouyel P, Ferrieres J, Ruidavets JB, Evans A, Bingham A, Ducimetiere P: Education, socioeconomic and lifestyle factors, and risk of coronary heart disease: the PRIME Study. Inter J Epidemiol 2005, 34:268-275.

22. Rao SV, Schulman AS, Curtis LH, Gersh BJ, Jollis JG: Socioeconomic status and outcome following acute myocardial infarction in elderly patients. Arch Intern Med 2004, 164:1128-1133.

23. Chang WC, Kaul P, Westerhout CM, Graham MM, Armstrong PW: Effects of socioeconomic status on mortality after acute myocardial infarction. Am J Med 2007, 120:33-39.

24. Alter DA, Chong A, Austin PC, Mustard C, Iron K, Williams Jl, Morgan CD, Tu JV, Irvine J, Naylor CD, SESAMI Study Group: Socioeconomic status and mortality after acute myocardial infarction. Ann Intern Med 2006, 144:82-93.

25. Tyden P, Hansen O, Engstrom G, Hedblad B, Janzon L: Myocardial infarction in an urban population: worse long term prognosis for patients from less affluent residential areas. J Epidemiol Community Health 2002, 56:785-790.

26. Drango N, Bobak M, Wege N, Peasy A, Verde PE, Kubinova R, Weyers S, Moebus S, Mohlenkamp S, Stang A, Erbel R, Jockel KH, Siegrist J, Pikhart H: Neighbourhood socioeconomic status and cardiovascular risk factors: a multilevel analysis of nine cities in the Czech Republic and Germany. BMC Public Health 2007, 7:255.

27. Rahimi AR, Spertus JA, Reid KJ, Bernheim SM, Krumholz HM: Financial barriers to health care and outcomes after acute myocardial infarction. JAMA 2007, 297:1063-1072.

28. Barakat K, Stevenson S, Wilkinson P, Suliman A, Ranjadayalan K, Timmis AD: Socioeconomic differentials in recurrent ischaemia and mortality after acute myocardial infarction. Heart 2001, 85:390-394.

29. Harald K, Salomaa V, Jousilahti P, Koskinen S, Vartiainen E: Nonparticipation and mortality in different socioeconomic groups: the FINRISK population surveys in 1972-92. J Edidemiol Community Health 2007, 61:449-454.

30. Ferrie JE, Kivimäki M, Singh-Manoux A, Shortt A, Martikainen P, Head J, Marmot M, Gimeno D, De Vogli R, Elovainio M, Shipley MJ: Non-response to baseline, non-response to follow-up and mortality in the Whitehall II cohort. Int J Epidemiol 2009, 38:831-837.

31. Tabibi J, Rabiee R, Sadoughi F: Performance evaluation of medical record department of specialized teaching hospitals of Iran Medical Science University. Feyz 2004, 8:57-65, [abstract in English].

32. Karbasi H, Ziaei M, Hosseini M: Evaluation of data recording in Teaching hospitals. J Medical Edu 2006, 9:93-97, [abstract in English].

33. Garmaroudi GR, Moradi A: Socio-economic status in Iran: a study of measurement index. Payesh 2010, 9:137-144.

34. Larijani B, Fakhrzadeh $H$, Mohaghegh M, Pourebrahim R, Akhlaghi MR: Burden of coronary heart disease on the Iranian oil industry (19992000). East Mediterr Health J 2003, 9:904-910.

doi:10.1186/1475-9276-10-9

Cite this article as: Donyavi et al:: Socioeconomic status and mortality after acute myocardial infarction: a study from Iran. International Journal for Equity in Health 2011 10:9.

\section{Submit your next manuscript to BioMed Central and take full advantage of:}

- Convenient online submission

- Thorough peer review

- No space constraints or color figure charges

- Immediate publication on acceptance

- Inclusion in PubMed, CAS, Scopus and Google Scholar

- Research which is freely available for redistribution 